\title{
URINARY INCONTINENCE;
}

POSTOPERATIVE EVALUATION IN WOMEN AFTER SUCCESSFUL GENITOURINARY FISTULA REPAIR

1. MBBS. MCPS. FCPS. MS Associate Professor (Obstetrics \& Gynaecology) Isra University Hospital Hyderabad.

2. MBBS. MPhil (Patho) Professor Isra University Hospital Hyderabad

3. MBBS. DGO. MCPS. FCPS Professor and Head of Department Isra University Hospital Hyderabad

\section{Correspondence Address:} Dr. Ambreen Amna Siddiqui Associate Professor Obstetrics \& Gynaecology G.U.II. Isra University Hospital Hyderabad.

ambreendoctor@gmail.com

Article received on:

25/07/2016

Accepted for publication:

15/04/2017

Received after proof reading: 05/06/2017

\begin{abstract}
Ambreen Amna ${ }^{1}$, Farkhunda Nadeem ${ }^{2}$, Pushpa Srichand ${ }^{3}$
ABSTRACT... Background: Genitourinary fistula remains a major cause of morbidity worldwide. Approximately 2 million of women suffer from urinary leakage. Since the establishment of Genito urinary Fistula center at Isra University Hospital -Hyderabad Sindh. We are able to share our experience of fistulous women at the time of admission and at follow up visit. Objectives: To determine the different types of urinary incontinence in a woman after genitourinary fistula repair. Study Design: A Follow-up Descriptive study. Study Setting: This Study was done at Fistula center Isra University Hospital Hyderabad GU - 11 from January 2011 to December 2013. All the women who were admitted with true incontinence followed by Obstetrical and major gynecological surgeries were included. However women with stress incontinence and urge incontinence and women who are not willing to include in the study were excluded. Result: Out of one hundred and ten (110) women included in this study, 59 (53.6\%) were found to have obstetrical fistula, while $43(39 \%)$ were suffering from latrogenic fistula. Continence status were explored at follow up visit. Out of 110 women, 108 (98.18\%) \& $96(87.27 \%)$ were having no signs of incontinence on examination at first visit and after six week and second visit after three month respectively. Only $7 \%$ women fell into incontinence grade 2 at six week follow up and only one percent had persistent symptoms of stress incontinence at 3 month respectively. Women fall on incontinence grade 3,4 and 5 were completely cured at 3 month. Conclusion: Success rate of genitor- urinary fistula repair is $98 \%$. Majority of women (96\%) on short term follow up at 6 weeks showed improved urinary symptoms. Moreover on follow up visit at 3 months, these women reported improved quality of life and social reintegration after fistula closure.
\end{abstract}

Key words: $\quad$ Genito urinary fistula. Vesico vaginal fistula. Follow up.

Article Citation: Amna A, Nadeem F, Srichand P. Urinary incontinence; postoperative evaluation in women after successful genitourinary fistula repair. Professional Med J 2017;24(6):824-827. DOI: 10.17957/TPMJ/17.3543

\section{INTRODUCTION}

Genitourinary fistula (GUF) has a profound physical and psychological impact not only before surgery but most of the women may suffer continuous stress if she leaks even a drop of urine after successful repair. These GUF most oftenly are caused by obstetric, surgical, radiation, malignant and miscellaneous causes. In most of the developing countries more than $90 \%$ of fistulae occur because of birth trauma, while in the UK and USA more than $70 \%$ are due to pelvic surgery. ${ }^{1}$ The persistent urinary incontinence, as a result of the genitourinary fistula causes these women are separated from their families as well as communities because of bad urinary odor. Approximately two million women with genitourinary fistula live with fistula and about
$100,000-500,000$ new cases are reported every year and most of them are iatrogenic. ${ }^{2}$ In Pakistan the incidence of vesico- vaginal fistula is 3 percent and it is about 2 percent in Sindh Province. Simple layered closure is most commonly employed and successful method of treating genitourinary fistula. The success rate is around $90 \%$ in various reported studies. ${ }^{3}$

The post-operative continuous leakage can be seen after the successful closure .According to studies about $33-50 \%$ of women may become continent after successful repair. ${ }^{4}$ It will not only distressing for woman but for surgeon as well who repair it. Women may regain her social activities after successful closure. Here we present a Hospital based follow up study that has assessed 
the different types of urinary incontinence in a woman after genitourinary fistula repair.

\section{METHODOLOGY}

This study was conducted at fistula center Isra University Hospital Hyderabad from January 2011 to December 2013. By using non-probability purposive sampling technique, Women who were admitted in GU-11 with genitor urinary fistula were included in this study. All women were asked about their demographic profiles, cause of fistula formation and type of surgery performed. Simple layered closure is most commonly employed technique followed by application of graft as well as uterine wound closure through abdominal route. These women were evaluated on follow-up visits after surgical repair: at six weeks and then three months by asking levels of incontinence grade (ICG). Incontinence grading system we used has been observing in Ethiopia Barhirdar Hamlin fistula center. ${ }^{5}$ The incontinence grading system (ICG) is determined on the history and then confirmed by observing the woman as the woman goes about her activities on follow up visit by asking simple question like control over urine and leakage associated with coughing and laughing, urgency and urge incontinence followed by vaginal examination on lithotomy and sims position to find out urinary leakage as well evidence of infection and presence of slough formation and healing of stitches.

According to ICG system the women were grouped as:

ICG grade 1: Women with completely dry (no leakage seen in vagina or in cloths) (considered as healthy)

ICG grade 2: Women with Incontinence on coughing, straining or exertion

ICG grade 3: Women with Incontinence on walking

ICG grade 4: Women with Incontinence on walking, sitting and/or lying but voiding some urine

ICG grade 5: Women with incontinence on walking, sitting and/or lying but not voiding any urine.
A standardized questionnaire was used and information entered into a database. All data were analyzed by using SPSS 16 .

\section{RESULTS}

The mean age of patients with urinary fistulae was $31.5 \pm 7.5$ years (range: $19-54$ years). Parity was $4.2 \pm 2.8$ (range:0-15) respectively .

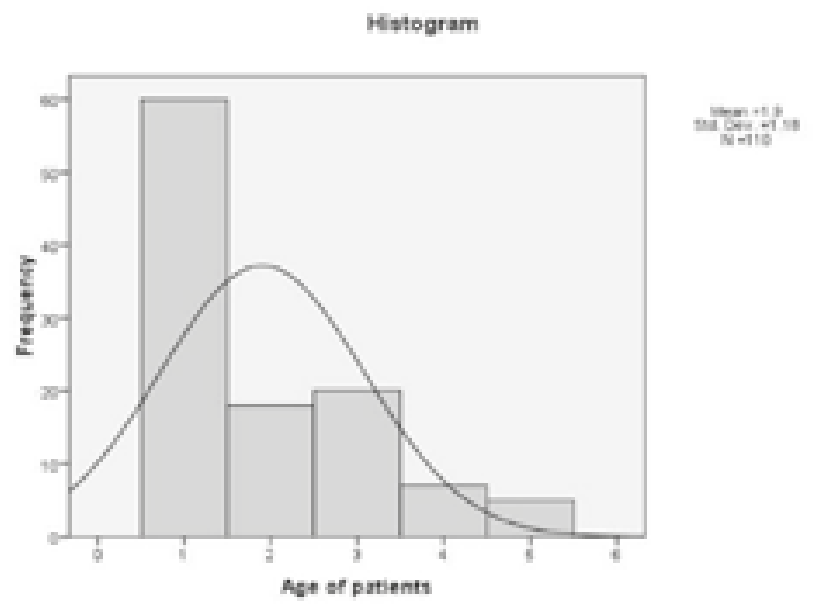

Bar Chart Histogram showing the distribution of age among study participant $(n=110)$

Cause of Fistula

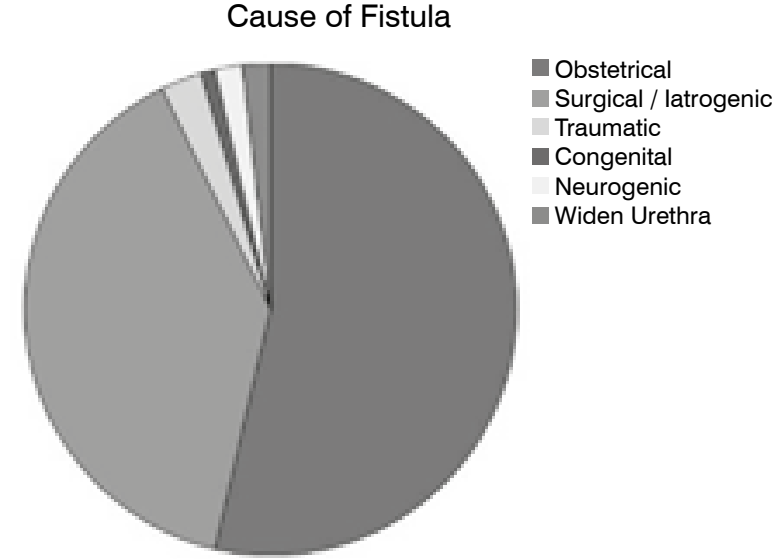

Pie Chart 1 showing the various etiological factors among study participant. $(n=110)$

\begin{tabular}{|l|c|c|}
\hline Causes & Number (110) & Percentage \\
\hline Obstetrical & 53.6 & $(59 \%)$ \\
\hline latrogenic & 43 & $(39.1 \%)$ \\
\hline Traumatic & 2.7 & $(3 \%)$ \\
\hline Congenital & 1 & $(0.9 \%)$ \\
\hline Neurogenic & 2 & $(1.8 \%)$ \\
\hline Widen urethra & 2 & $(1.8 \%)$ \\
\hline \multicolumn{2}{|c|}{ Table-l. Depicts the various etiological factors } \\
\multicolumn{2}{|c|}{ among study participant. $\mathrm{n}=110$}
\end{tabular}




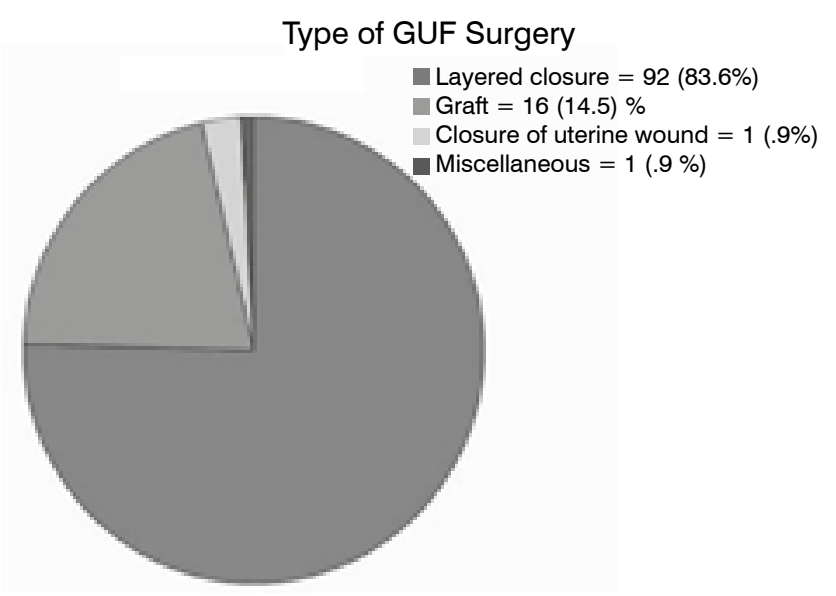

Pie chart 11. Depict the types of surgery performed among study participant: $n=110$

\section{DISCUSSION}

The post-operative bladder dysfunction and urinary incontinence after successful repair leads to significant distress to women resulting in both psychological and physical trauma. Studies on bladder dysfunction in our setting are very few and limited. The post-operative residual incontinence is a major issue. Here we present a follow up hospital based study based on evaluation of urinary incontinence in women after successful genito urinary fistula repair. We have demonstrated that urinary incontinence, nocturia and urgency were the most frequently reported symptoms, while stress and urge incontinence occurring with equal frequency. Few women reported urinary leakage like nocturia, stress and urge incontinence in short term follow up following successful closure while most of them were almost symptom free on long term follow up.

Present study has showed that most of the fistulous women were belonging to younger age group. The mean age of women with urinary fistulae were $31.5 \pm 7.5$ years (range: 19-54 years) ${ }^{7}$ Current study has also showed that 56 $\%$ of women were illiterate which is consistent with results of other study which has reported a strong correlation between illiteracy and incidence of VVF. ${ }^{6}$ In present study most common causative factor for GUF was obstetrical trauma 59 (53.6\%) followed by iatrogenic injury 43 (39\%) encountered during pelvic surgeries. The incidence of iatrogenic injury is $54 \%$ according to one of the study conducted in Pakistan which is more or less near to our study. ${ }^{7}$

One of the epidemiological study under taken in New Castle in a cohort of 3000 women 20 years after delivery found high prevalence of pelvic floor dysfunction and another study found that nocturia, urgency, and frequency were found in $63 \%, 48 \%$ and $30 \%$ of women respectively in short term follow up. ${ }^{8}$

According to various studies success of surgical closure rate in first attempt is $70-95 \%$ which in consistent with finding of the present study i.e.87.27. ${ }^{9}$ According to present results $7.27 \%$, $2.72 \%$ and $1.8 \%$ of the women presented with ICG 1, 2 and 3 respectively, while only one woman complaint of ICG 4 at short term i.e., 6 weeks follow up. These complain were remarkably absent on long term follow up i.e., 3 month follow up as shown by the results that only 2 women out of total of 110 participants presented with ICG 2 while rest of them were completely symptom free. (Table 3) These results reflect a high success rate of genitourinary fistula repair in women presented with urinary incontinence due to GUF.

\begin{tabular}{|c|l|c|c|}
\hline $\begin{array}{l}\text { Incontinence grade at } \\
\text { the time of discharge }\end{array}$ & \multicolumn{1}{|c|}{ Description of incontinence } & $\begin{array}{c}\text { Incontinence grade at } \\
\mathbf{6} \text { weeks follow up }\end{array}$ & $\begin{array}{c}\text { Incontinence grade } \\
\text { at 3 month follow up }\end{array}$ \\
\hline 1 & Cured no incontinence & $96(87.27 \%)$ & $108(98.18 \%)$ \\
\hline 2 & Incontinent with cough, strain or exertion & $8(7.27 \%)$ & $2(1.8 \%)$ \\
\hline 3 & Incontinent on walking & $3(2.72 \%)$ & NIL \\
\hline 4 & $\begin{array}{l}\text { Incontinent on walking, sitting and lying but } \\
\text { voiding some urine }\end{array}$ & $2(1.8 \%)$ & NIL \\
\hline 5 & $\begin{array}{l}\text { Incontinent on walking, sitting and lying but } \\
\text { not voiding any urine }\end{array}$ & $1(0.9 \%)$ & NIL \\
\hline
\end{tabular}

Table-III. Postoperative evaluation of urinary Incontinence at Isra University Hospital -Hyderabad $(n=110)$ 
The results also reveal that the symptoms which persist in some of the women after repair tend to resolve over a period of time like after 2-3 months as are shown by our results. (Table 3 ) This finding is also consistent with Browning and Member who have reported improvement in persisting urinary incontinence after repair over time (6 months) together with that improvement, there was evidence of improvement in several aspects of quality of life, with involvement into society. ${ }^{4,10}$

However, success rate of GUF repair may not be high in some region of the world as a study carried out in Ethiopia on women with obstetric fistulae has showed that $55 \%$ of women were incontinent despite successful closure of their fistula. ${ }^{4}$

\section{CONCLUSION}

Taken together present study demonstrated a very high success rate of genitor- urinary fistula repair. Majority of women on short term follow up at 6 weeks showed improved urinary symptoms. Moreover on follow up visit at 3 months, these women were almost symptom free and reported improved quality of life with social reintegration.

\section{Copyright(C) 15 Apr, 2017.}

\section{REFERENCE}

1. Hilton P. Urogenital fistulae. In: Maclean A, Cardozo L, editors. Incontinence in Women Proceedings of the 42nd RCOG Study Group. London: RCOG; 2002. pp. 163-81.
2. Sacdev PS. Hassan N. Abbasi RM. Das CM. Genito urinary fistula: A major morbidity in developing countries J Ayub Med Coll Abbottabad 2009; 21 (2).

3. Khan RM, Raza N, Jehanzaib $M$, Sultana $R$. Vesicovaginal fistula: an experience of 30 cases at Ayub Teaching Hospital Abbottabad J Ayub Med Coll Abottabad Jul - Sep 2005; 17(3):48-50.

4. Browning A, Menber B. Women with obstetric fistula in Ethiopia: a 6-month follow up after surgical treatment. BJOG 2008; 115:1564-9.

5. Dolan L, Dixon W, Hilton P. Urinary symptoms and quality of life in women following urogenital fistula repair: a long-term follow-up study. BJOG 2008; 115:1570-1574.

6. Hilton $P$. The urodynamic findings in patients with urogenital fistulae. Br J Urol 1998; 81:539-42.

7. Raashid Y, Tmajeed T, Majeed N, Shahzad N. latrogenic vesicovaginal fistula. J Coll Physicians Surg Pak. 2010 Jul; 20(7):436-8.

8. Jackson S, Donovan J, Brookes S, Eckford S, Swithinbank L, Abrams P. The Bristol Female Lower Urinary Tract Symptoms Questionnaire: Development and psychometric testing. Br J Urol 1996; 77:805-12.

9. Dolan LM. The prevalence and obstetric antecedents of pelvic floor dysfunction. MD Thesis, Newcastle University, Newcastle upon Tyne, UK, 2007.

10. Murray C, Goh JT, Fynes M, Carey MP. Urinary and faecal incontinence following delayed primary repair of obstetric genital fistula. BJOG 2002; 109:828-32.

\begin{tabular}{|c|c|c|c|}
\hline \multicolumn{4}{|c|}{ AUTHORSHIP AND CONTRIBUTION DECLARATION } \\
\hline Sr. \# & Author-s Full Name & Contribution to the paper & Author $=\mathbf{s}$ Signature \\
\hline $\begin{array}{l}2 \\
3\end{array}$ & $\begin{array}{l}\text { Dr. Ambreen Amna } \\
\text { Dr. Farkhunda Nadeem } \\
\text { Prof. Dr. Pushpa Srichand }\end{array}$ & $\begin{array}{l}\text { Concept, Design and drafting } \\
\text { Critical revision of important } \\
\text { concept } \\
\text { Acquiaction of data } \\
\text { intepretation of data }\end{array}$ & 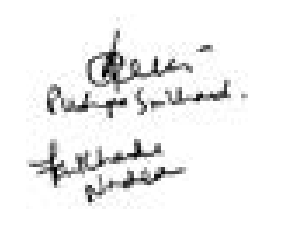 \\
\hline
\end{tabular}

